\title{
Stress in higher education: a study of mismatched instruction as a contributing factor in female Emirati undergraduate students
}

\author{
Usama ALAlami \\ Mahaba Salem Saleh Mohammed AI-Saleh \\ Tofi Rahal \\ Zayed University, UAE
}

\section{Introduction}

In today's global economy student-based learning is increasingly becoming central to improved education and productivity. As one consequence of this, education institutions around the world are shifting towards the use of learning and thinking styles as a basis to improve students' learning (Alliance for Excellent Education, 2012)

Dunn and Dunn (1992) proposed that providing learning input matched to a students' learning style leads to higher scores on academic assessments. Attempting to match educational settings to the preferred learning styles of students places students within their academic comfort zone, and therefore may impact positively on their learning experience, motivation and achievement. Conversely, this paper proposes that a continuing mismatch between educational settings/activities and learning preferences/strengths may frustrate students and put them at a disadvantage which results in a higher level of physiological anxiety and stress.

The aim of this project is to study the relationship between learning styles, teaching methods and level of students' stress. More specifically, the effect of mismatched instruction on students' stress levels will be investigated. Stress manifests in physiological and psychological responses (Engelmann, Landgraf, \& Wotjak, 2004), and a pilot study carried out by the authors demonstrated a possible link between mismatched instruction and the development of physiological signs of stress (ALAlami et al., 2009). In this paper data will be analyzed in an effort to shed more light on the learning process and ultimately to improve students' learning. Our hypothesis is that subjecting students to a mismatched learning style will manifest in increased levels of stress at both the physiological and psychological levels.

\section{Key concepts}

\section{Learning styles}

This research is an offshoot from a previous and extensive study by a team of educators led by Rahal to profile the learning styles of students at Zayed University, and make necessary recommendations to improve the learning of students. The work was part of a 2-year project funded by Zayed University, 2007-2009. For more information and results on this work please refer to Rahal and Palfreyman (2009). Initially, the team worked in collaboration with a team of experts from the Dunn \& Dunn staff in the US, using the learning styles model developed by Dunn \& Dunn $(1972,1993,1999)$ who define learning styles as "the way in which individuals begin to concentrate on, process, internalize, and retain new and difficult information" (Dunn \& Dunn, 1992). Dunn \& Dunn, 1999 have developed and refined Learning

ALAlami, A., Al-Saleh, M. \& Rahal, T. (2013). Stress in higher education: a study of mismatched instruction as a contributing factor in female Emirati undergraduate students. Learning and Teaching in Higher Education: Gulf 
Style Inventories to assess and profile student learning style characteristics. These inventories offer teachers as well as students help in making the appropriate choice regarding preferences within six different strands of learning styles domain as shown in Figure 1 below. Several other models, such as VAK (Visual, Auditory, Kinesthetic) and VARK (Visual, Auditory, Read/Write, Kinesthetic) are subsumed within Dunn \& Dunn's Perceptual Strand.

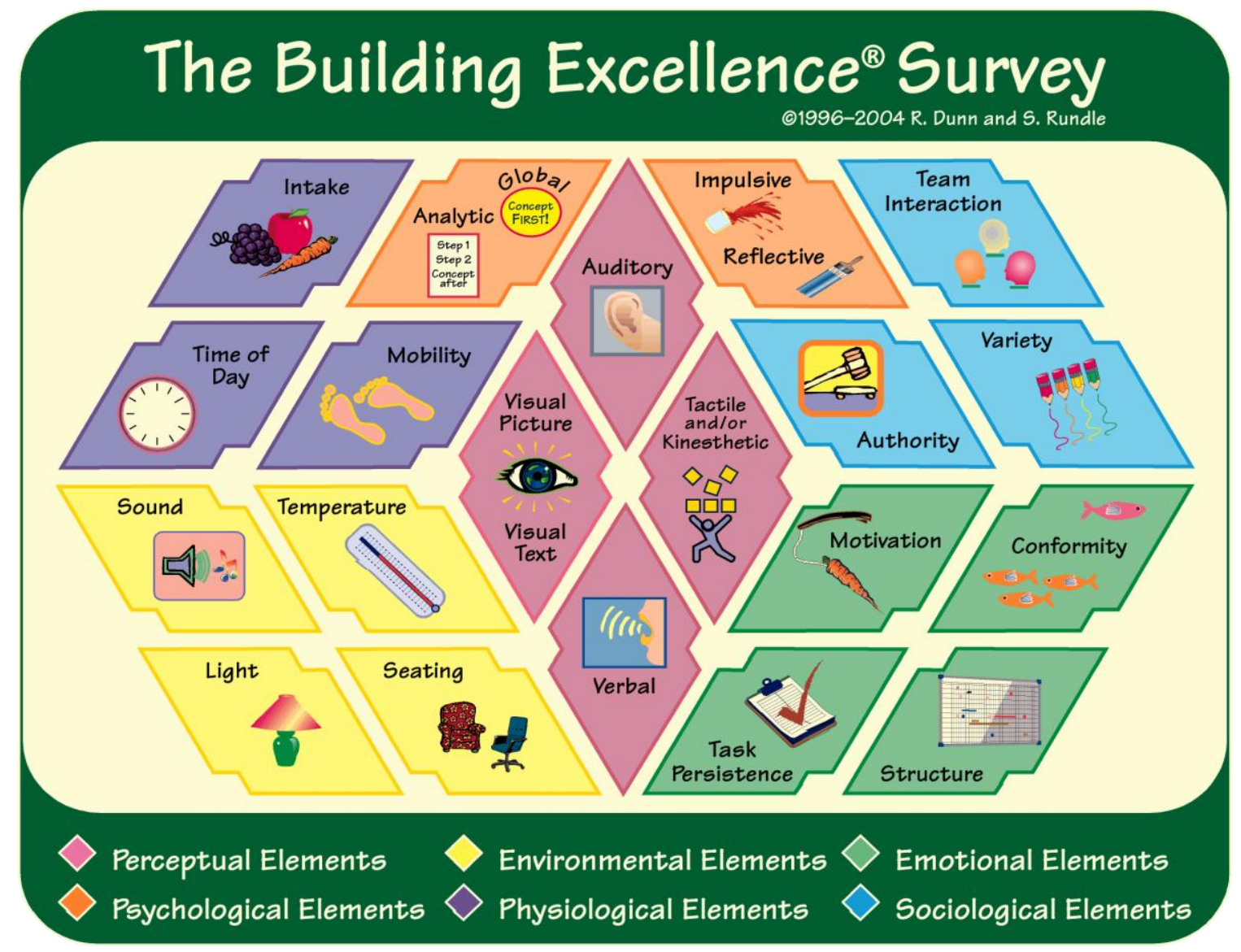

Figure 1: Learning styles model (Dunn and Dunn, 1993).

Most learning style models are based on the following assumptions (Dunn \& Dunn, 1993):

- Most individuals are able to learn.

- Individual learning preferences exist and can be measured reliably.

- Everyone has a set of learning styles at different strengths. Different people have very different sets of learning styles.

- Students score higher in an environment which promotes matched rather than mismatched treatments.

- Most teachers can be trained to use learning styles to develop suitable instruction.

- Many students can learn to capitalize on their learning style strengths to tackle a new or difficult academic situation. 
For this project the VARK learning styles model (see Figure 2) was chosen because of the ease of use and its practicality. It provides a simple profile of students' basic sensory learning preference. According to the VARK model, every individual has a predisposed dominant learning style, instinctively favoring one of four styles: Visual, Auditory, Read/Write or Kinesthetic. Some students process information most effectively by using a visual (graphic) learning style, while others rely more heavily on either an auditory style, a read/write learning style or kinesthetic style of learning (Hawk \& Shah, 2007). The four learning style elements in VARK are part of the perceptual strand in the Dunns' model. It is worth noting that the $\mathrm{V}$ in the VARK model is equivalent to the symbolic or graphic visual for the Dunns', while the $R$ (Read/Write) in VARK corresponds to Visual Text in the Dunns'. Leite et al., (2010) provide support for the validity and reliability of the VARK inventory as an instrument to assess learning styles, despite noting certain limitations of the instrument including its narrow scope, since it deals only with perceptual elements of the learning styles domain. For instance, it does not deal with personality and psychological categories or other elements included in other learning styles models.

\begin{tabular}{|l|l|}
\hline Learning Mode & Example \\
\hline Visual & $\begin{array}{l}\text { Maps, Diagrams, Charts, Graphs, Flow charts, Animation, Videos, Colored } \\
\text { material. }\end{array}$ \\
\hline Aural & Listening to lectures, Tutorials, Group discussions. \\
\hline Read/Write & PowerPoint slides, Discussion boards, Web pages. \\
\hline Kinesthetic & $\begin{array}{l}\text { Videos of "real" things, Demonstrations, Simulations, Case Studies, } \\
\text { Practical Applications, Role playing, Actions, Manipulating }\end{array}$ \\
\hline
\end{tabular}

Figure 2: VARK model (Fleming, 2001).

\section{Stress and anxiety}

In the human body, the stress response is mediated by a hormonal system called the hypothalamicpituitary-adrenal axis, or HPA-axis for short. When the body perceives stress, the HPA axis, along with the sympathetic nervous system (famous for its 'fight or flight' response), are activated together (Engelmann et al., 2004). Although the stress response is helpful and necessary when dealing with short lived stressors, issues result when the perceived stress remains sustained over a period of time. The sympathetic nervous system (SNS) tends to dominate over its counterbalance, the parasympathetic nervous system (PNS), which governs less active ('rest and digest') behaviours. As a result, the individual has difficulty settling back down to their normal physical and emotional state, even if the perceived stress is subsequently removed. Activation of the sympathetic nervous system is associated with an increase in mean arterial blood pressure (Carroll et al., 1995; Engelmann et al., 2004).

A study carried out at the University of California (Epel, 2009) confirmed that elevated levels of cortisol were linked directly to stress. When cortisol levels are raised during stress, it can have negative impacts on the hippocampus, a part of the brain responsible for memory, learning and response to stress and anxiety. This is done by diverting the glucose away from the hippocampus to the muscles. This was confirmed in a study by Buchanan et al. (2009), which showed that damage to the hippocampus resulted in abolishing response to psychosocial stress in human participants.

Stress is increasingly reported among staff and students working in institutions of Higher Education; a stress survey conducted by the University and Colleges Union in the UK showed that the main sources of

ALAlami, A., Al-Saleh, M. \& Rahal, T. (2013). Stress in higher education: a study of mismatched instruction as a contributing factor in female Emirati undergraduate students. Learning and Teaching in Higher Education: Gulf 
work-related stress were linked to demands to meet targets and deadlines (Smith, 2007). Studies carried out in student populations tend to identify sources of stress as poor quality of life due to socio-economic factors, with some relating stress to the demanding nature of academic life in Higher Education. A study carried out by ALAlami et al. (2008) investigated physiological and psychological stress in academics working at an institute of higher education in the UK. The results of the study identified various stressors in the academic environment, and linked psychological profiles to physiological changes in heart rate and blood pressure.

The relationship between achievement and anxiety has had a long history in psychology (Levitt, 1980) with research suggesting that optimal performance is achieved when there is a moderate level of anxiety. In reviewing the literature on academic performance and affective variables, Dwinell and Higbee (1989) found that learning styles impacted at-risk college students in such a way that their sample of students preferred visual learning. The authors noted that if these students were to be successful in traditional auditory and textual delivery modes, then they would need assistance in adapting to lecturers' styles. Moreover, Deutsch and Tobias (1980) found that student stress appeared to be alleviated by being placed in a situation where students had the opportunity to rewind an instructional lecture. To investigate whether learning about environmental problems increases students' anxiety related to an event (state anxiety) and anxiety related to personality (trait anxiety), researchers in Turkey found that students' state but not trait anxiety scores increased (Oluk, Ozuredi, \& Sakaci, 2009). These researchers concluded that learning about environmental issues increased students' anxiety levels. The role of other variables such as how one views one's own intelligence, prior knowledge of or experience with a subject, and perceptions of an instructor have been tested to see their influence on anxiety and achievement. In their study of Masters students taking a research course, Rothenberg and Harrington (1994) found that self-perceived level of intelligence was inversely related to their anxiety, and those who perceived the teacher favorably tended to achieve better than those who did not. Anxiety and stress in student populations is therefore a complex matter with various factors impacting on it. The current research attempts to investigate mismatched instruction in students as a contributing factor to the development of stress.

A study reported by Divaris et al. (2008) investigated the academic environment in a dental education setting - a context generally recognized to be one that is demanding, with students having to cope with high levels of stress. The study identified psychological and physiological manifestation of stress in this population of students. Interestingly, in addition to outlining the classical factors that help reduce stress levels amongst the student population such as class size, leisure time and assessment procedure, the working group concluded that subject matter content should be delivered in a variety of methods that accommodate different learning styles and preferences of learners. However, no studies have found a direct correlation between increasing stress levels in students in relation to their learning style preferences. The proposed project hopes to achieve this, and to suggest interventions to help overcome that stress.

\section{Methods}

\section{Participants}

80 female student participants from Zayed University took part in this project, which had been granted ethical approval by Zayed University Research Ethics Committee. The students were registered for three separate sections (26 students in section 1, 26 in section 2 and 28 in section 3 ) and thus divided into three groups as a sample of convenience. The age range was 18-25.

ALAlami, A., Al-Saleh, M. \& Rahal, T. (2013). Stress in higher education: a study of mismatched instruction as a contributing factor in female Emirati undergraduate students. Learning and Teaching in Higher Education: Gulf 


\section{Protocol}

Prior to the start of the session, all participants completed the VARK questionnaire. Participants also completed the DASS21 questionnaire for assessment of stress. The DASS21 questionnaire was completed before and after delivery of the session, in order to establish baseline levels of stress, and compare them to levels of stress after the session was delivered. The DASS21 questionnaire assesses various aspects of stress such as tension, irritability, inability to relax and nervousness (Lovibond and Lovibond, 1995). The DASS21 was chosen because it appears to be a reliable and easy to administer measure, and is ideal for both clinical and research purposes (Norton, 2007): the latter study suggested that the internal consistency, and convergent and divergent validity of the DASS21 are similar across racial groups. The DASS21 severity ratings are shown in Figure 3:

\begin{tabular}{|l|l|}
\hline Stress Category & DASS Score \\
\hline Normal & $0-14$ \\
\hline Mild & $15-18$ \\
\hline Moderate & $19-25$ \\
\hline Severe & $26-33$ \\
\hline Extremely severe & $34+$ \\
\hline
\end{tabular}

Figure 3: DASS21 stress levels (Psychology Department, UNSW 2011 ; Antony et al., 1998)

The principal investigator and research assistant collected the paper questionnaire results from all three groups. Results for group 1 (26 participants) were analyzed manually using the paper version of the DASS21 questionnaire. They were then compared to analysis using an online tool http://serene.me.uk/tests/dass-21.pdf. The results were exactly the same; and the remainder of the group responses were analyzed using the online tool. Results were categorized into normal, moderate, mild and severe.

Students in each of the three groups attended one, 40 minute session delivered by an academic. Each session was identical and was on the topic of the human endocrine system. The main learning outcome of the session was to familiarize the students with the structure/function relationship in the endocrine system and how that relates to the maintenance of the state of homeostasis. The session was strongly kinesthetic and auditory in nature, involving role play and a variety of activities that encouraged the participants and the educator to move around the lecture room. These included the participants and the educator assuming the roles of protein and steroid hormones and acting out a scenario on how they are transported in the blood, followed by how they act on the target cell. The educator gave auditory instructions to guide the students throughout the session; no visual or written stimuli were provided and no written instructions were distributed. Participants with Kinesthetic or Auditory learning style preference thus experienced a session which matched their learning style, unlike students who were Read/Write or Visual, whose learning style mismatched the session.

Heart rate and blood pressure were measured using the ri-Champion blood pressure recording equipment. Heart rate and blood pressure were measured at baseline (time 0 ) and then at 10 minute intervals, up to 40 minutes, with each reading lasting on average for 20 seconds. The short duration of the measurement is not anticipated to have interfered with the results. The participants were instructed

ALAlami, A., Al-Saleh, M. \& Rahal, T. (2013). Stress in higher education: a study of mismatched instruction as a contributing factor in female Emirati undergraduate students. Learning and Teaching in Higher Education: Gulf 
at the start of the session about the use of the blood pressure measuring equipment. Heart rate was recorded in beats per minute (bpm); systolic and diastolic blood pressure measurements were recorded in $\mathrm{mmHg}$, and the values were used to calculate the Mean Arterial Pressure (MAP) using the following equation:

$$
\text { MAP = Diastolic Pressure }+(\text { Pulse Pressure/3) }
$$

where pulse pressure was calculated as the difference between the systolic and diastolic blood pressure readings.

In order to ensure that the items of clothing worn by participants did not interfere with the blood pressure measuring equipment, sample readings for 9 participants were taken with and without clothing covering the arm of the participant, as a pilot study to ensure the validity of using the equipment. It appeared that the item of clothing did not significantly influence the mean arterial pressure (MAP) recording for participants (Figure 4).

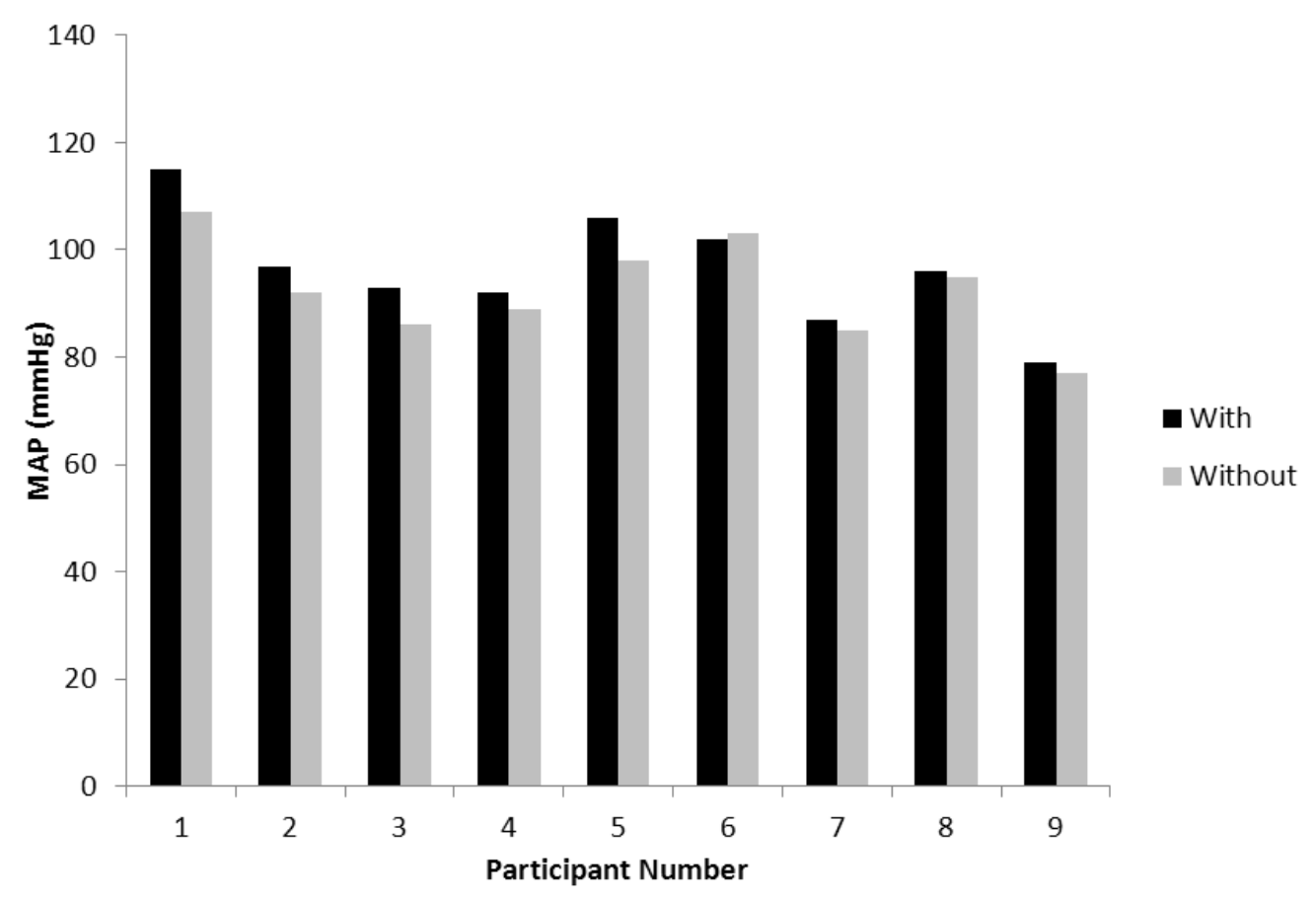

Figure 4: Effect of item of clothing on blood pressure measurements.

Statistical significance was determined for results using the t-test performed in Microsoft Excel. Significance level was determined at $p<0.05$ (signified by ${ }^{*}$ ) and $p<0.01$ (signified by ${ }^{* *}$ ).

\section{Research Design and Intervening factors}

Although changes in MAP and heart rate may occur as a result of actual measurement of these parameters, the changes are usually not significant and are short-term in nature. A study carried out by Mancia et al. (1983) on the effect of blood pressure measurement by the doctor on the patients' blood pressure concluded that some changes occurred in the first 4 minutes in some patients as a result of measuring blood pressure and heart rate by the doctor, but that the readings normalized after that. This is sometime referred to as the 'white coat effect/syndrome', and is usually neutralized when patients 
measure their own blood pressure either at a clinical setting or in their home environment. The fact that the measurement process was automated would have also reduced the need for the participants in the study to inflate and deflate the blood pressure cuff, and the time and effort this may require; thus ensuring minimal stress on the participant and more consistent and accurate readings. The participants had previously used the same equipment in the lab to measure their blood pressure and heart rate and were therefore accustomed to their use. Intervening factors affecting stress such as academic workload, personal/social/lifestyle may influence the measurement, both physiological and psychological. However, baseline readings were recorded at the start of the session to control for such factors.

\section{Findings}

VARK analysis was performed for all three groups. Figure 5 shows the learning profile for participants across the three groups. Group 1 demonstrate a strong Kinesthetic $(K=34 \%)$ and Auditory $(A=29 \%)$ preference compared to Visual $(\mathrm{V}=18 \%)$ and Reading $(\mathrm{R}=19)$. The same trend was obtained in groups 2 and 3 as shown in Table 1.

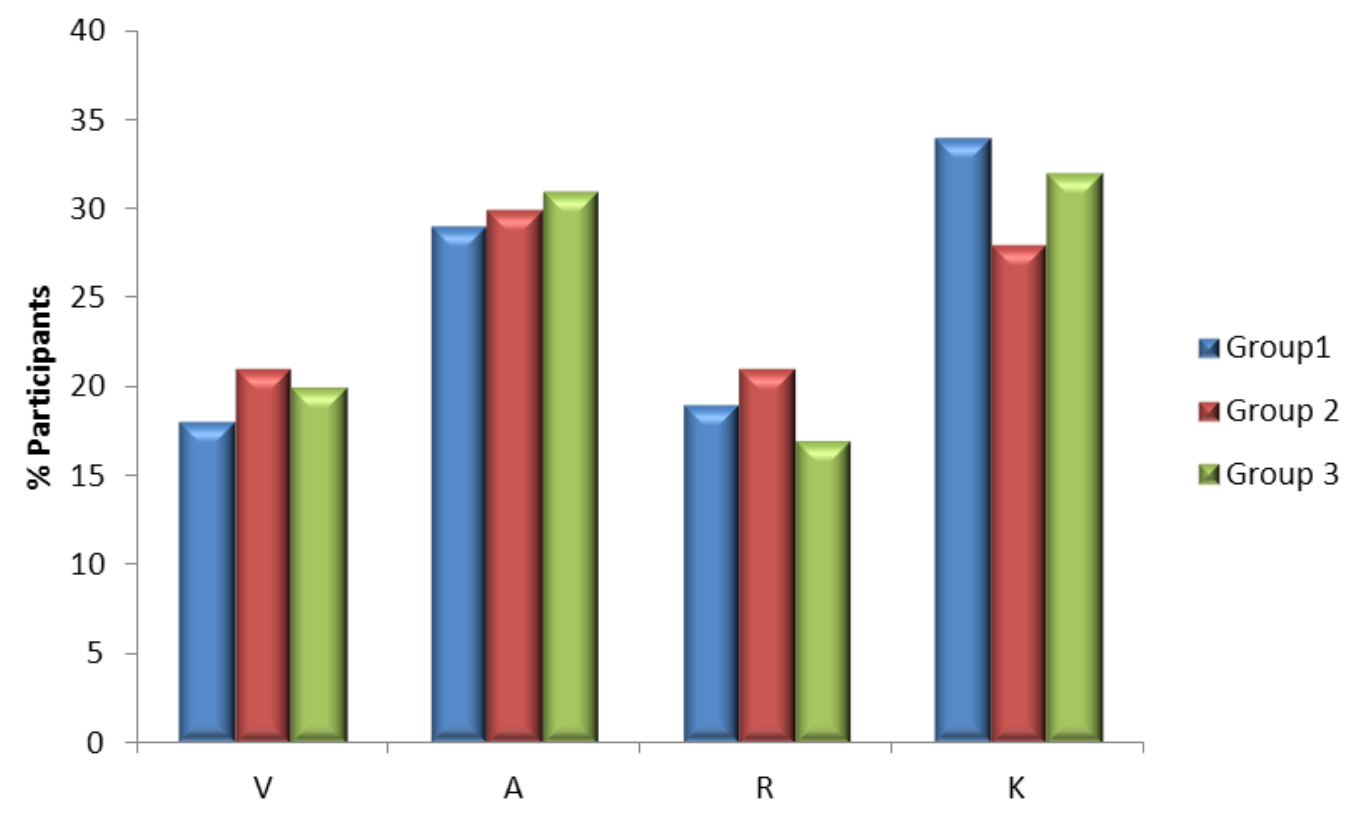

Figure 5: Learning style assessment.

Table 1: Learning style profile within each group.

\begin{tabular}{|c|c|c|c|}
\hline Learning Style & \% Participants Group 1 & \% Participants Group 2 & \% Participants Group 3 \\
\hline V & 18 & 21 & 20 \\
\hline
\end{tabular}

ALAlami, A., Al-Saleh, M. \& Rahal, T. (2013). Stress in higher education: a study of mismatched instruction as a contributing factor in female Emirati undergraduate students. Learning and Teaching in Higher Education: Gulf 


\begin{tabular}{|c|c|c|c|}
\hline$A$ & 29 & 30 & 31 \\
\hline$R$ & 19 & 21 & 17 \\
\hline$K$ & 34 & 28 & 32 \\
\hline
\end{tabular}

Figure 6 shows the students' heart rate (HR) from the beginning of the lecture continuing to 40 minutes from starting for all three groups of participants. The letters $V, A, R$ and $K$ correspond to the four learning styles, whilst 1, 2 and 3 refer to the group number. The heart rate scale runs vertically, while the time scale is on the horizontal axis. At the start of the session, the average heart rate of students who preferred the $K$ learning style was $62 \mathrm{bpm}$, similar to those who preferred $A$; the average rate for $R$ students was $67 \mathrm{bpm}$, and for $V$ students was 68 . By the end of the lecture, their heart rates increased to $K=78, A=77, R=95, V=90 \mathrm{bpm}$, and the increase was statistically significant at $p<0.05$ (shown on the graph as *). The heart rate of the two categories $V$ and $R$ increased more than $K$ and $A$, but $R$ increased the most, with statistical significance at $p<0.01$ (shown on the graph as ${ }^{* *}$ ). AK versus VR categories were also compared at the 40 minute time mark for statistical significance; results showed that the increase in the VR categories was higher compared to the AK categories at $p<0.05$. Statistical differences among the three groups was also analyzed. Although no statistically significant differences were calculated between the Auditory participants in groups 1 and 2 at time 0 , statistical differences at $p<0.05$ were recorded between the auditory participants at time 0 in groups 1 and 2 , when compared to group 3 . Statistical significance at $p<0.05$ was also recorded between the three groups of participants at times 0 and time 40 for the other learning styles.

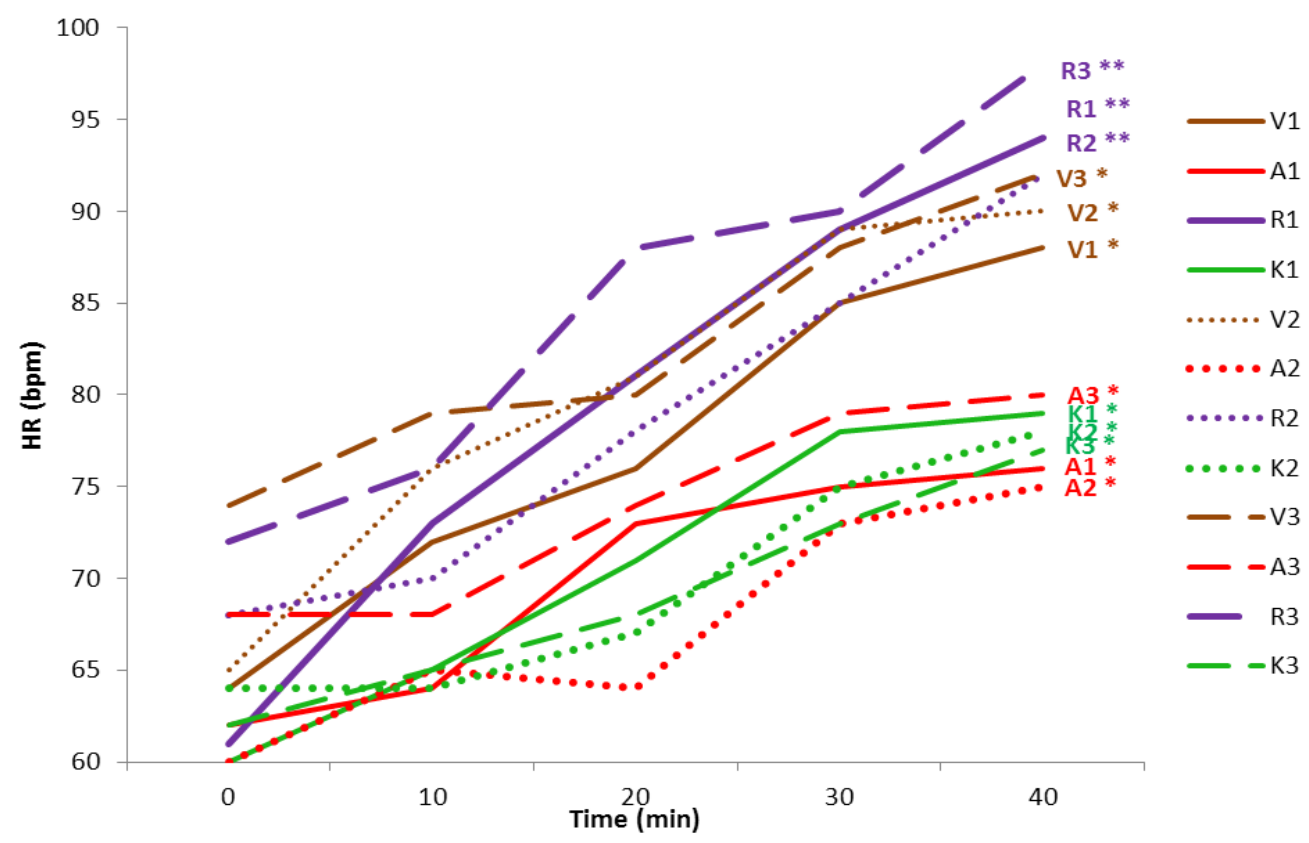

Figure 6: Heart rate for each learning style preference across all three groups

Figure 7 shows the student's mean arterial pressure from the beginning of the lecture continuing to 40 minutes from starting for all three groups of participants. The letters $V, A, R$ and $K$ correspond to the four learning styles, whilst 1,2 and 3 refer to the group number The pressure scale runs vertically, while the time scale is on the horizontal axis. The mean arterial pressure of those who preferred the Kinesthetic

ALAlami, A., Al-Saleh, M. \& Rahal, T. (2013). Stress in higher education: a study of mismatched instruction as a contributing factor in female Emirati undergraduate students. Learning and Teaching in Higher Education: Gulf 
learning style was $76 \mathrm{mmHg}$; the ones who preferred $A$, had an average of $75 \mathrm{mmHg} ; \mathrm{R}=81 \mathrm{mmHg}$ and $\mathrm{V}=79 \mathrm{mmHg}$. By the end of the lecture, their mean arterial pressures had increased to $\mathrm{K}=91 \mathrm{mmHg}, \mathrm{A}=$ $91 \mathrm{mmHg}, \mathrm{R}=103 \mathrm{mmHg}$, and $\mathrm{V}=100 \mathrm{mmHg}$ and the increase was statistically significant at $p<0.05$ (shown on the graph as ${ }^{*}$ ). The arterial pressure of the two categories $V$ and $R$ thus increased more than $K$ and $A$, but $R$ increased the most, with a statistically significant increase $(p<0.01$, shown on the graph as $\left.{ }^{* *}\right)$. AK versus VR categories were also compared for statistical significance at 40 minutes and results showed that the increase in the VR students was higher compared to the AK students at $p<0.05$. Statistical differences between the three groups was also analyzed and no statistically significant differences were found between the various groups.

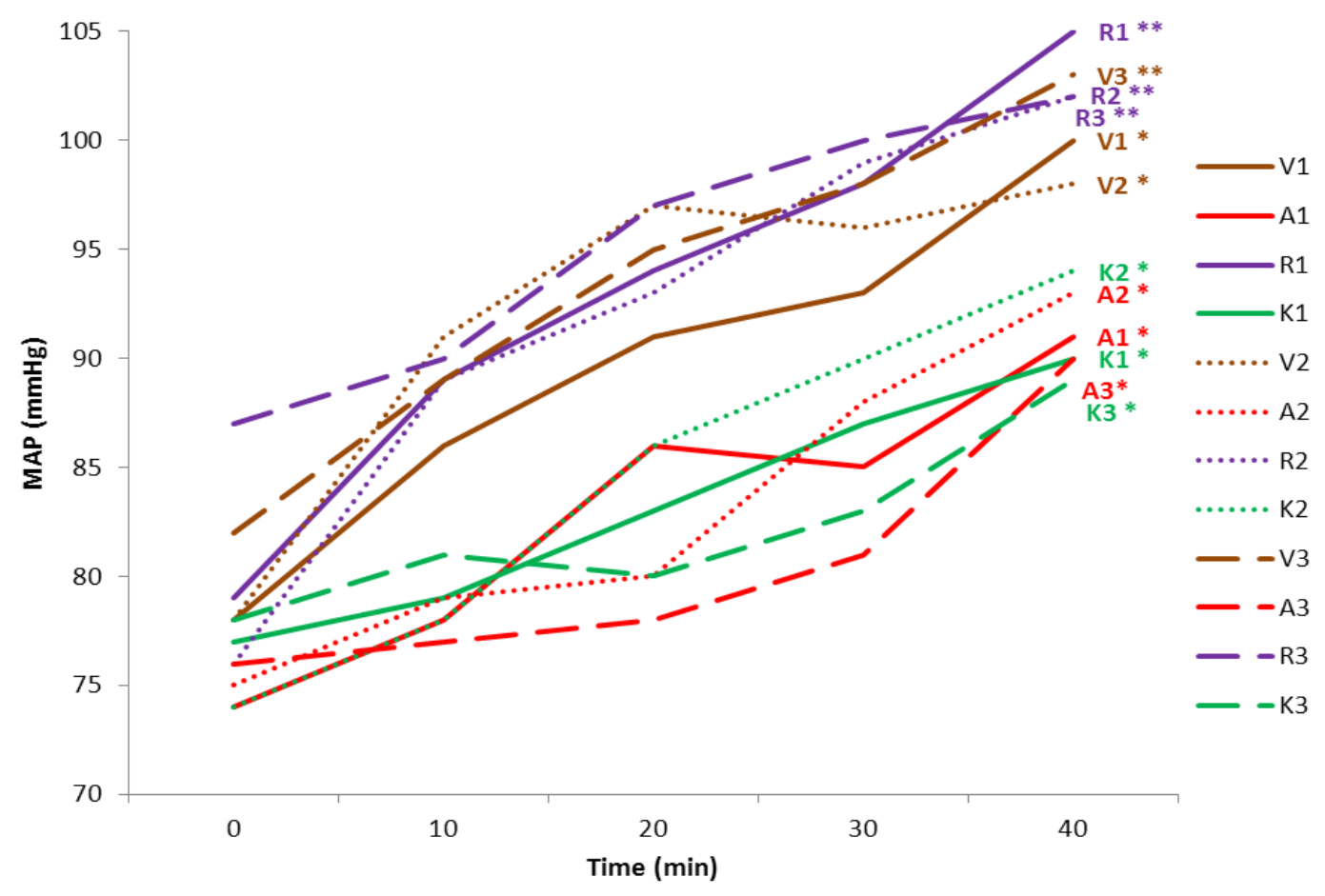

Figure 7: Mean arterial pressure for each learning style preference across all three groups.

Error! Reference source not found. shows the student's level of stress both before and after delivery of the lecture for group 1. The severity labels are used to describe the full range of scores in the population, so 'mild' for example means that the person is above the population mean but probably still far below the typical severity of someone seeking help (i.e. it does not mean a mild level of disorder). Comparison is made before and after the lecture between the two categories, the Auditory/Kinesthetic (AK) and those who were assessed as Visual/Reading (VR). The percentages shown are percentages of the whole group. No significant differences were recorded in the normal or mild stress categories between the AK and the VR students (32\% of AK and 33\% of VR students were rated 'normal stress' before compared to $31 \%$ and $30 \%$ after respectively). However, there was an increase in the percentage of participants experiencing moderate stress in the VR group after the delivery of the lecture (Moderate stress $18 \%$ before to $21 \%$ after) and the increase was statistically significant at $p<0.05$

ALAlami, A., Al-Saleh, M. \& Rahal, T. (2013). Stress in higher education: a study of mismatched instruction as a contributing factor in female Emirati undergraduate students. Learning and Teaching in Higher Education: Gulf 


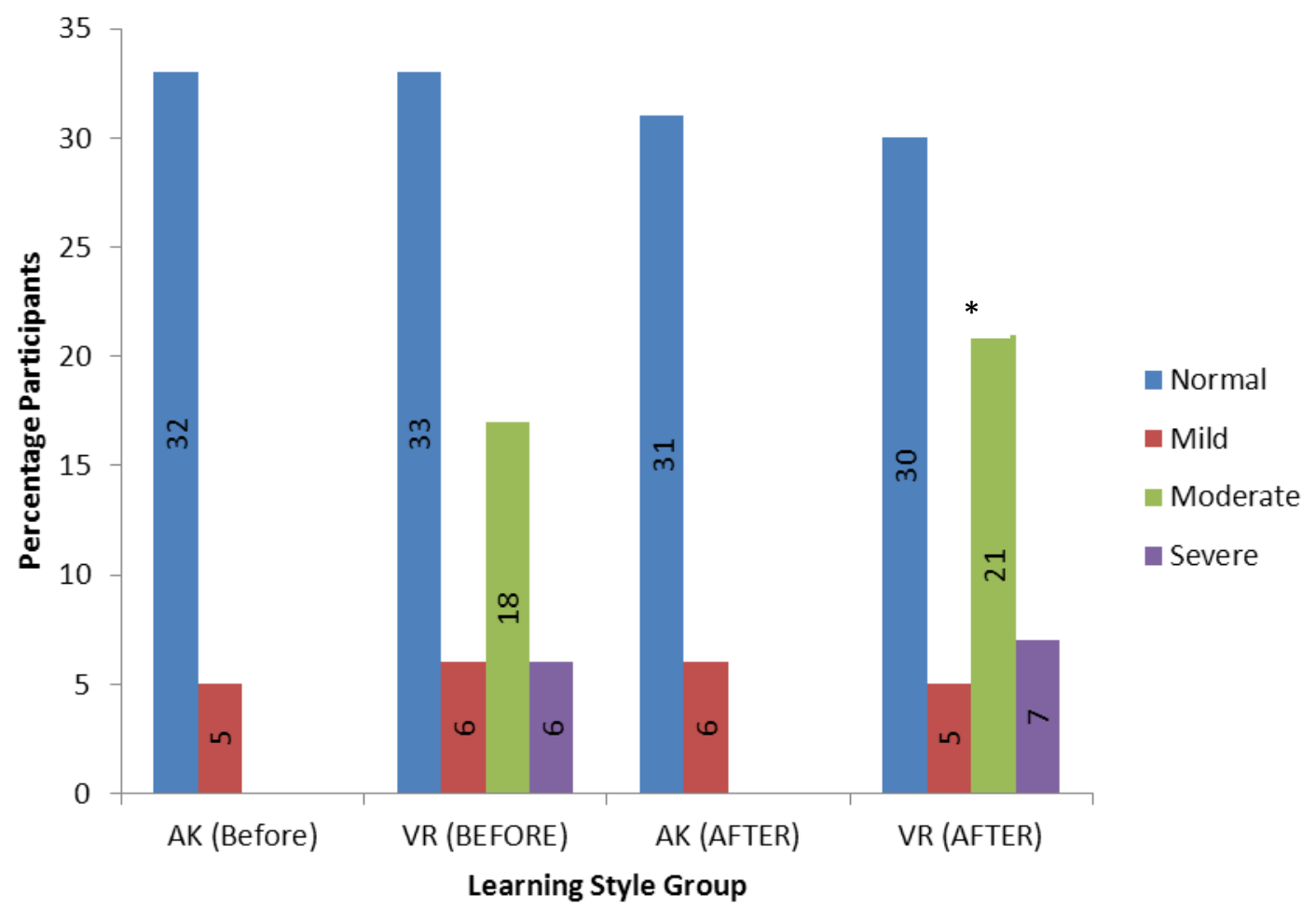

Figure 8: Relationship between learning style preference and stress as assessed by the DASS21 questionnaire.

\section{Conclusions}

The above results have provided evidence to accept the working hypothesis stated earlier, suggesting that exposing students to a mismatched learning style manifests itself in terms of physiological stress as seen by a sympathetic response marked by an increase in heart rate and blood pressure. Although all students demonstrated an increase in heart rate and blood pressure, the increase in those subjected to a mismatched learning style was significantly higher. The heart rate recorded in the Read/Visual group at the end of the 40 minute session was averaging 91 beats/min, which is close to recording a diagnosis of tachycardia, an increase in the heart rate of human beings which creates stress on the heart and less efficient circulation of the blood around the rest of the body: long term effects may include strokes and heart attacks (Whinnett, Sohaib \& Davies, 2011). The results showed a clear difference in heart rate and MAP between the two groups (AK and VR) which was statistically significant. Physiological stress has a nervous, endocrine (pituitary, thyroid and adrenal glands) and an immune aspect to it (Engelmann et al., 2004). Physiological effects of stress may be immediate, intermediate or prolonged. These will involve sympathetic, endocrine and immune system activation at various points (Engelmann et al., 2004). However, all will result in a detrimental impact on health.

This study also demonstrated that moderate levels of psychological stress may set in when students are exposed to mismatched learning instruction. It should be noted, however, that although mismatched learning instruction is an important factor identified in this study, multiple factors contribute to the development of stress in higher education such as financial status, social influence, and lifestyle changes. 
Chronic stress is a serious health issue and may result in long term damage to health, such as heart attacks, strokes and cancer. Students attend lectures in higher education daily; it is clear that subjecting them to a learning style that does not match their preference results in stress, and may therefore have long-term negative health effects. In addition to the physiological effects of stress, a stressed student population is not one that is innovative, creative or willing to learn. It is therefore vital to try to broaden the teaching styles used by academics to cater for the spectrum of learning styles we find amongst the student population. Equally important is to train students to become comfortable to learn using a variety of learning styles. For instance, teachers can prepare interactive visual aids for those students who have a Visual preference, while making sure to use role playing activities for those who are more kinesthetic. As for those who are Auditory, activities that include discussion circles can be very helpful. But, as Rahal \& Palfreyman (2009) and Rahal (2010) suggest, accommodating instruction to students' learning styles is an important first step to improve interest in learning and increase motivation in students.

Although this study was innovative, it is important to note that the sample included in this study were all Emirati females, and therefore further work needs to be carried out to expand on the study population in terms of both gender and cultural background. It is only then that the results may be generalized.

Stress is both physiological and psychological in nature, with the physiological aspect encompassing the immune and endocrine systems as well. Future work could consider assessing endocrine and immune effects of stress, using measurement of parameters such as the levels of the hormone cortisol. The research design would also benefit from introducing a learning assessment tool (e.g. a test/quiz) to measure student comprehension of the material under the various learning conditions.

\section{References}

ALAlami, U., Cooper, R.G, Jackson, C., Hu, B., \& Ashford, R. (2008) Proposed study: A preliminary study and proposed methodology: Utilisation of pervasive computing (NeXus-4) and questionnaires to determine selected physiological and psychological parameters in participants working at a Higher Education Institute in the UK. The Third International Conference on Pervasive Computing and Applications (ICPCA08): IEEE Proceedings, 768-771.

ALAlami, U., Rahal, T., ALTareb, B., Jaffar, K., Ashford, R., Ejtehadi, H., Cooper, R.G., \& Nelson, P. (2009) Investigating Students Learning Styles and the Effect of Mismatched Instruction on Students' Levels of Stress. $5^{\text {th }}$ Annual Research Conference. CHSCR, Birmingham City University.

Alliance for Excellent Education (2012). Culture shift: teaching in a learner-centered environment powered by digital learning. Retrieved December 122012 from http://www.all4ed.org/files/CultureShift.pdf.

Antony, M.M., Bieling, P.J., Cox, B.J., Enns, M.W., \& Swinson, R.P. (1998) Psychometric properties of the 42-item and 21-item versions of the Depression Anxiety Stress Scales in clinical groups and a community sample. Washington DC, ETATS-UNIS: American Psychological Association.

Buchanan, T.W, Tranel, D., \& Kirschbaum, C. (2009) Hippocampal damage abolishes the cortisol response to psychosocial stress in humans. Horm Behav., 56(1), 44-50

Carroll, D., Smith, G.D., Sheffield, D., Shipley, M.J., \& Marmot, M.G. (1995) Pressor reactions to psychological stress and prediction of future blood pressure: data from the Whitehall II study. $B M$, 310, 771-775.

ALAlami, A., Al-Saleh, M. \& Rahal, T. (2013). Stress in higher education: a study of mismatched instruction as a contributing factor in female Emirati undergraduate students. Learning and Teaching in Higher Education: Gulf 
Deutsch, T. \& Tobias, S. (1980). Prior achievement, anxiety and instructional method. Paper presented at the annual meeting of the American Psychological Association ( $\left.88^{\text {th }}\right)$. Montreal, Quebec: Canada.

September 1-5, 1980.

Divaris, K., Barlow, P.J., Chendea, S.A., Cheong, W.S., Dounis, A., Dragan, I.F., Hamlin, J., Hosseinzadeh, L., Kuin, D., Mitrirattanakul, S., Mo'nes, M., Molnar, N., Perryer, G., Pickup, J., Raval, N., Shanahan, D., Songpaisan, Y., Taneva, E., Yaghoub-Zadeh, S., West, K., \& Vrazic, D. (2008) The academic environment: the students' perspective. Eur J Dent Educ. Suppl 1, 120-130.

Dunn, R., \& Dunn, K. (1972). Practical approaches to individualizing instruction: Contracts and other effective teaching strategies. Englewood Cliffs, NJ: Parker Publishing Division of Prentice Hall.

Dunn, R., \& Dunn, K. (1992). Teaching elementary students through their individual learning styles: Practical approaches for grades 3-6. Boston, MA: Allyn \& Bacon.

Dunn, R., \& Dunn, K. (1993). Teaching secondary students through their individual learning styles: Practical approaches for grades 7-12. Boston, MA: Allyn \& Bacon.

Dunn, R., \& Dunn, K. (1999). The complete guide to the learning styles in-service system. Boston, MA: Allyn \& Bacon.

Dwinell, P. L. \& Higbee, J. L. (1989). The relationship of affective variables to student performance: Research findings. Paper presented at the Annual Conference of the National Association of Developmental Education. Cincinnati, $\mathrm{OH}$.

Engelmann, M., Landgraf, R., \& Wotjak, C. (2004). The hypothalamic-neurohypophysial system regulates the hypothalamic-pituitary-adrenal axis under stress: an old concept revisited. Front Neuroendocrinol, 25 (3-4), 132-49.

Epel, ES. (2009) Psychological and metabolic stress: a recipe for accelerated cellular aging? Hormones. $8(1), 7-22$.

Fleming N.D. (2001) Teaching and Learning Styles: VARK Strategies Honolulu Community College ISBN 0473-07956-9.

Hawk, T.F., \& Shah, A.J. (2007) Using learning style instruments to enhance student learning. Decision Sciences Journal of Innovative Education, 5(1), 1-19.

Leite, W. L., Svinicki, M. \& Shi, Y. (2010). Attempted validation of the scores of the VARK: learning styles inventory with multitrait-multimethod confirmatory factor analysis models. Educational and Psychological Measurement, 70(2), 323-339.

Levitt, E. E . (1980). The psychology of anxiety ( $2^{\text {nd }}$ ed). Hillsdale, NJ: Erlbaum.

Lovibond, S.H. \& Lovibond, P.F. (1995). Manual for the depression anxiety stress scales (2 ${ }^{\text {nd }}$ Ed). Sydney: Psychology Foundation.

Mancia, G., Bertinieri, G., Grassi, G., Parati, G., Pomidossi, G., Ferrari, A., Gregorini, L., \& Zanchetti, A. (1983). Effects of blood-pressure measurement by the doctor on patient's blood pressure and heart rate. Lancet, 2(8352), 695-8.

Norton, P.J. (2007). Depression Anxiety and stress scales (DASS-21): psychometric analysis across four racial groups. Anxiety Stress Coping, 20(3), 253-265

ALAlami, A., Al-Saleh, M. \& Rahal, T. (2013). Stress in higher education: a study of mismatched instruction as a contributing factor in female Emirati undergraduate students. Learning and Teaching in Higher Education: Gulf 
Oluk, S., Ozuredi, O, \& Sakaci, T. (2009). Determination of state-trait anxiety levels of university students in the learning process of global environmental problems. U.S. China Education Review, 6(1), 49-53.

Psychology Department, UNSW (2011). Retrieved January 20 2013, from - www.psy.unsw.edu.au/dass.

Rahal, T. \& Palfreyman, D. (2009). Assessing learning styles of students at Zayed University. Learning and teaching in higher education: Gulf perspectives, 6(2). http://www.zua.c.ae//the06_02_01_rahal.htm

Rahal, T. (2010). Learning styles: learning that empowers students? Learning and teaching in higher education: Gulf perspectives 7(2).

Rothenberg, L. F., \& Harrington, C. F. (1994). The relationship between anxiety and achievement in adult learners. Paper presented at the Annual Meeting of the American Educational Research Association. New Orleans, LA: April 4-8, 1994.

Smith, A. (2007). Lecturers report high levels of stress. Retrieved January 26 2007, from http://www.guardian.co.uk/higher-education-network.

Whinnett, Z.I., Sohaib, S.M., \& Davies, D.W. (2012). Diagnosis and management of supraventricular tachycardia. British Medical Journal, 345:e7769.

ALAlami, A., Al-Saleh, M. \& Rahal, T. (2013). Stress in higher education: a study of mismatched instruction as a contributing factor in female Emirati undergraduate students. Learning and Teaching in Higher Education: Gulf 